\title{
4. CATALOGUE OF TEACHING IN RISK AND INSURANCE ECONOMICS
}

This part of the study is reproduced integrally in the French edition, published by the Institut Universitaire d'Etudes Européennes, 122 rue de Lausanne, Geneva.

In this part we give a detailed description (100 pages) of the various courses offered by the Universities and Institutes of specialized Instruction listed below.

\subsection{Risk and Society}

University of Kent at Canterbury

Graduate Institute of European Studies (Geneva)

University of Sussex

\subsection{Theory of Risk and Uncertainty}

University of Amsterdam

The Norwegian School of Economics and Business Administration

Manchester Business School

University of Southampton

University of Social Sciences at Toulouse

University of Vienna

4.3. Sectorial Macroeconomics of Risk and Insurance

University of Aix-Marseille

University of Belgrade

Free University of Brussels (ULB)

Free University of Brussels (VUB)

University of Lausanne

University of Louvain

University of Lyon

University of Paris I (IAP)

University of Paris I

National School of Statistics and Economic Administration (ENSAE) at Paris

University of Turin

4.4. Financial Macroeconomics of Risk and Insurance

University College of North Wales

City of London Polytechnic

Independent University of Madrid

University of Orléans

University of Paris II

University of Sheffield 


\subsection{Social Policy}

University of Berne

University of Erlangen-Nuremberg

University of Geneva

University of Linz

University of Naples

University of Neuchâtel

University of Rome (Economics)

University of Rome (Statistics)

University of Venice

Swiss Federal Institute of Technology (Zurich)

\subsection{Management of Insurance Firms}

Central University of Barcelona

Independent University of Bilbao

The Catholic Institute of Advanced Business Studies in Brussels (ICHEC)

University of Cologne

The Copenhagen School of Economics and Business Administration

University of Frankfurt-Main

University of Genoa

University of Hamburg

University of Louvain

Complutense University of Madrid

University of Mannheim

Bocconi University of Milan

University of Munich

University of Paris IX

Advanced School of Economics and Business Studies of Paris (ESSEC)

University of Parma

Universiy of Siena

University of Commerce (Vienna)

Vienna Technical University

\subsection{Risk Management}

Polytechnic of Central London

The City University of London

University of Nottingham

St Gall Graduate School of Economics, Business and Public Administration 